\title{
Privacy, Shame and the Anxieties of Identity
}

\author{
Lisa M. Austin \\ Version Post-print/accepted manuscript \\ Citation Austin, Lisa M., Privacy, Shame and the Anxieties of Identity (January 1, \\ (published version) 2012). http://dx.doi.org/10.2139/ssrn.2061748
}

How to cite TSpace items

\begin{abstract}
Always cite the published version, so the author(s) will receive recognition through services that track citation counts, e.g. Scopus. If you need to cite the page number of the author manuscript from TSpace because you cannot access the published version, then cite the TSpace version in addition to the published version using the permanent URI (handle) found on the record page.
\end{abstract}

This article was made openly accessible by $U$ of $T$ Faculty. Please tell us how this access benefits you. Your story matters. 


\title{
PRIVACY, SHAME, AND THE ANXIETIES OF IDENTITY
}

\author{
Lisa M. Austin
}

Many privacy advocates, and scholars, seek to liberate privacy from shame. We need to understand that privacy norms do more than insulate individuals from the exposure of shameful secrets and intimate information, the argument goes, in order to deal with contemporary privacy issues that concern the collection of information that is often not sensitive or intimate and may even be publicly available. This essay argues that privacy does not need to be liberated from shame-to the contrary, it is shame that can liberate privacy. A proper understanding of shame reveals that it involves a complex form of self-consciousness-how you feel about how others view you; it is triggered by a disjunct between how you would like others to see you and the consciousness that they do not see you in this way. Privacy norms can insulate us from shame because they protect our self-presentation from the disruptions that can cause us to feel shame. Accounts of privacy go wrong when they do not understand this idea of identity that is at stake in privacy norms. By relying upon different ideas of identity, such as self-revelation or selfdetermination, both control-based and limited-access accounts of privacy misunderstand the social dimensions of identity and end up with an impoverished account of privacy norms. By ignoring the centrality of identity, "contextual" accounts of privacy lose analytic rigour by running together a broad set of interests and norms under the category of "privacy." A focus on the constitutive relation between privacy and identity can also show why the idea that privacy should be protected through legal rights is misplaced. Justifications for legal rights rely upon ideas of autonomy and harm but privacy's focus on the conditions of self-presentation sound in an altogether different register. This essay argues that legal rights such as the tort of invasion of privacy lie, at best, on the periphery of the legal protection of privacy and that the emerging international standards of Fair Information Practices provide a better framework. The best way to understand this framework is not through the language of rights but through a set of alternative ideas about the role of law in enabling and empowering individuals to act within a context of settled expectations necessary for the production of identity and agency. The role of privacy law is not simply to protect identity but in fact to help produce it.

\footnotetext{
"Associate Professor, University of Toronto Faculty of Law. This paper is largely a response to a question posed to me by Thomas Nagel regarding the suitability of protecting privacy through legal rights and I would like to thank him for it ("Privacy and the Private Law: The Dilemma of Justification," October 18, 2007 presentation at the Dworkin/Nagel Colloquium in Legal, Moral and Political Philosophy, New York University). I also presented portions of this argument at the Melbourne Law School conference "Media, Communications and Public Speech" (November 25, 2010) and I would like to thank the participants for their comments.
} 


\section{Introduction}

Shame often hovers near privacy. We can ask whether information is private by asking whether its disclosure would "humiliate" and we can show damages by pointing to the "humiliation and distress" that follow from disclosure. ${ }^{1}$ Although what is private is often difficult to define, easy cases include information associated with intimacy and secrecy that lead to stigmatization and shaming if exposed. Shame is even thought to be the appropriate response to the disclosure of some information, and its absence ground for social censure. "A man without shame" proclaims the Daily Mail in relation to Max Mosley's failure "to shrink from the public gaze" after reports that he indulged in "Nazi-style" orgies--instead daring to defend himself and sue for invasion of privacy. ${ }^{2}$ “

But, insist privacy advocates and many scholars, privacy is more than the protection of shameful secrets and intimate information, or the insulation of individuals from social shaming. Privacy concerns abound in relation to information practices that deal with the collection and use of information and not just its disclosure, information that is not on its own "sensitive" and which may even be publicly available. Although shame might help us identify easy cases of privacy violations, it also misleads us into adopting an overly narrow view of privacy that cannot account for these other privacy concerns. Shame, it seems, is a fair weather friend. Better to cut it loose than adopt it into an account of privacy.

\footnotetext{
${ }^{1}$ Hosking v. Runting, NZCA 34 (2004) at para. 128.

${ }^{2}$ Geoffrey Wansell, A man without shame: How can sex scandel F1 boss Max Mosley paint himself as the injured party, MAILONLINE (April 24, 2008), http://www.dailymail.co.uk/news/article-561577/A-man-shame-How-sexscandal-F1-boss-Max-Mosley-paint-injured-party.html. Mosley was vindicated in his breach of confidentiality suit, which in Britain is understood to protect privacy: Mosley v. News Group Newspapers Ltd., EWHC 1777 (QB, 2008 ).
} 
Although this might seem like a reasonable move, in this paper I argue that it is wrong. Privacy does not need to be liberated from shame-it is shame that can liberate privacy. I want to defend the view that shame is indeed central to our understanding of privacy. However, I also argue that this does not confine privacy to a narrow sphere of shameful secrets. To the contrary, I argue that properly understanding the nature of shame and its relationship to privacy illuminates privacy's constitutive relation with identity. It is this relation that can liberate privacy from some of its narrower iterations that make it difficult to respond to contemporary information practices. As I will outline, the problem is not with the concept of privacy but with the ideas of identity that inform it, and the ability of law to protect these identity concerns.

I will first look at shame and show that it involves a special kind of anxiety about identity — one that involves how you feel about the way in which others view you. The idea of identity at issue is best understood in terms of self-presentation, which I understand as the way in which individuals negotiate their social identity In light of this consciousness of how they are seen by others and their desire to be seen in a particular way; privacy norms operate to protect the basic terms of self-presentation. I will then use this understanding of self-presentation-and its relation to privacy - to show how it can illuminate many of the anxieties that currently plague privacy theory, including questions regarding how to define privacy as well as how to account for its contextual nature. My claim is that much of this reflects misunderstandings regarding the constitutive relationship between privacy and identity understood in terms of self-presentationthese other views of privacy either adopt a different underlying view of identity or fail entirely to see the way in which identity provides a unifying analytic framework for an account of privacy norms. Finally, I will look at the question of the legal protection of privacy and argue that the law displays a number of anxieties when it comes to protecting the conditions of identity 
formation. My claim is that legal rights are the wrong framework for thinking about privacy law. Instead of a focus on legal liability for the violation of rights, we should look to other understandings of the law that show how law can ensure the kind of settled expectations necessary to secure the conditions of self-presentation. This suggests that the central legal paradigm for privacy law should not be private law rights such as those articulated in tort law, but the idea of Fair Information Practices that underpin many models of data protection law across the world.

\section{Shame and Privacy}

We often use the term "shameful" to indicate a kind of moral censure regarding socially deviant behavior. For example, we might say that an individual "ought to be ashamed of" something. If that individual very deliberately flouts social norms then we might call them "shameless." Finally, if we think that someone is engaged in socially deviant behavior then we might think that they should be exposed to "shaming," which is really just to say that they should be exposed to social practices that publicly proclaim: "you ought to be ashamed."

These uses of the language of shame are connected to our ideas of privacy. To take a recurring example from the popular media, discussions of adolescent on-line behaviour often discuss shame and privacy interchangeably: in revealing everything about their lives, from the banal to the intimate, youth are seen to both have no sense of privacy and no sense of shame. Their "shameless" behavior involves flouting privacy norms. Shame and privacy are linked in other ways to online behavior, such as the proliferation of "shaming" sites that detail and thus 
expose the perceived infractions of various social norms by ordinary people. ${ }^{3}$ In this way exposure - which is at the heart of many privacy violations - can expose one to "shaming" practices if the behavior exposed violates social norms.

This cursory view suggests that privacy is connected, in some constitutive manner, to the social norms that also inform our sense of the "shameless" and "shameful." Exposing yourself, or exposing others, can result in the social judgments of shamefulness in relation to the person exposed. Privacy norms protect the acceptable terms of such exposure. Privacy law and theory is replete with references to this relationship. For example, sometimes limits to exposure are justified in terms of protecting individuals from its stigmatizing effects, such as when the identity of sexual assault claimants is protected by publication bans. ${ }^{4}$ In some privacy tort cases, courts have indicated that the special nature of injury at issue in privacy violations is "humiliation and distress" arising from the exposure at issue. ${ }^{5}$ Many theorists have pointed to the inhibiting effects of exposure - in order to avoid certain social reactions, individuals avoid doing things that they would otherwise judge as important, interesting or desirable. ${ }^{6}$ Privacy norms insulate us from such social pressure, thereby promoting aspects of individual autonomy. ${ }^{7}$

My claim here is that we can be more precise about the nature of this social pressure and, in doing so, gain more clarity regarding privacy. The social pressure that privacy insulates us from should be understood in terms of shame. This is why the result of many privacy violations is a feeling of humiliation and distress - people feel shame. However, the idea of shame is much

\footnotetext{
${ }^{3}$ For example, in the wake of the 2011 Stanley Cup riots in Vancouver, Canada, a number of shaming sites like identifyrioters.com proliferated as a means to get the public to help identify the rioters who were perceived to have violated important social norms.

${ }^{4}$ Dagenais v. Canadian Broadcasting Corp., 3 SCR 835 (1994).

${ }^{5}$ Hosking, NZCA at para. 128

${ }^{6}$ See Ruth Gavison, Privacy and the Limits of Law, 89 YALE L. J. 421 (1980); BeAte Rössler, The VALUE OF PRIVACY (2005).

${ }^{7}$ See Ferdinand David Schoeman, Privacy And Social Freedom (1992); Julie E Cohen, Examined Lives : Informational Privacy and the Subject as Object, 52 STAN. L. REV. 1374 (2000).
} 
more complex than this and unravelling its structure can help us understand the nature of privacy and the relationship between privacy and identity. As I argue below, the constitutive connection between privacy and shame does not lie in the underlying social norms regarding what ought and what ought not to be exposed. Instead, shame arises out of a complex form of self-consciousness in relation to these norms, tying exposure more centrally to one's own sense of identity than to the underlying social norms. In other words, what a focus on shame shows us is the constitutive relationship between privacy and identity.

To start, a more complex understanding of shame needs to account for the feeling of shame and not just the normative judgment that one "ought to feel ashamed." Consider the example of seemingly uninhibited adolescents who disclose intimate information and even nude photos on-line. Given the way that such practices violate deeply entrenched social norms regarding the privacy of sexual and intimate behaviour, many of us consider such behavior shameful. What is interesting is that although we might think that such individuals ought to feel shame, many in fact do not. In an article in New York Magazine several years ago a 19 year old prolific blogger was interviewed regarding her very public on-line life. When asked for her opinion regarding the scenario of an ex-boyfriend posting a sex-tape on the internet as an act of revenge, she replied:

My philosophy about putting things online is that I don't have any secrets.... And whatever you do, you should be able to do it so that you're not ashamed of it. And in that sense, I put myself out there online because I don't care-I'm proud of what I do and I'm not ashamed of any aspect of that. And if someone forms a judgment about me, that's their opinion.

If that girl's video got published, if she did it in the first place, she should be thickskinned enough to just brush it off .... I understand that it's really humiliating and everything. But if something like that happened to me, I hope I'd just say, well, that was a terrible think for a guy to do, to put it online. But I did it and that's me. So I am a sexual person and I shouldn't have to hide my sexuality. I did this for my boyfriend just like you 
probably do this for your boyfriend, just that yours is not published. But to me, it's all the same. It's either documented online for other people to see or it's not, but either way you're still doing it. So my philosophy is, why hide it? ${ }^{8}$

The student here discusses both the normative judgments involved in questions of shamewhether one ought to be ashamed of something — and the feeling of shame itself. In being a sexual person, she does not accept any social disapproval regarding her sexual practices as, according to her, they are nothing to be ashamed of. At the same time, she denies feeling shame (although, symptomatic of some conflict here, she acknowledges the possibility of feeling humiliated), arguing that she does not care what anyone thinks about her.

Leaving aside the conflation between knowing that someone is a sexual person and viewing evidence of this on-line, this sense of not caring what others think is quite a startling admission. The apparent "shamelessness" of such behavior lies not so much in the violation of social norms per se but in the express flouting of the opinion of other people regarding the violation. She is shameless precisely because she does not care what others think.

Therefore although both "shameful" and "shameless" imply a normative judgment regarding socially inappropriate behavior, they also make reference to the feeling of shamewhether one ought to feel it and whether one in fact does. This latter sense of shamelessness lines up with Aristotle's definition of a shameless person as one "who thinks of no one's opinion" and "who says and does anything on any occasion or before any people." 9 For Aristotle, shame is a "[p]assion" that is defined "as a kind of fear of disrepute." 10 Someone who has no shame, therefore, is someone who has no such fear because they simply do not care what anyone thinks

\footnotetext{
${ }^{8}$ Emily Nussbaum, Kids, the Internet, and the End of Privacy: The Greatest Generation Gap Since Rock and Roll, N.Y. MAG. Feb 12, 2007.

9 Aristotle, NicOMACHEAN EthiCs, 1108a31-5, in COMPlETE WORKS OF ARISTOTLE: THE REVISED OXFORD Translation (revised Ox ed. 1992); ARISTOTle, EudEMian ETHICS, 1233b26-30, in COMPLETE WORKS OF ARISTOTLE: THE REVISED OXFORD TRANSLATION (revised Ox ed. 1992).

${ }^{10}$ ARISTOTLE, NiCOMACHEAN ETHICS, supra note 9 at 1128b10-11.
} 
about them. Such shamelessness is an extreme to be avoided. Instead, the mean we are to strive for is modesty, which stands between bashfulness and shamelessness. If the shameless person does not care for anyone's opinion and the bashful person is overly concerned with everyone's opinion, the modest person "thinks only of [the opinion] of apparently good men." person therefore feels shame in the right way — not as a general fear of disrepute but as a fear of disrepute in front of people of high moral stature.

This is helpful, but some caution is in order with respect to the claim that shame is a general fear of disrepute. Such a broad fear could encompass situations where individuals fear the ill effects of a bad reputation without actually feeling shame. For example, one could imagine an individual who fears the effects of on-line sexual disclosures on her employment prospects without necessarily also feeling ashamed of such disclosures. She might not care what prospective employers think about her sexuality except in an entirely instrumental sense of whether this diminishes the likelihood of being offered a job. Instead, the fear of disrepute involved in the feeling of shame is self-reflexive. In Shame and Necessity, Bernard Williams argues that shame is an emotion that points to "what I am."12 Although it is aroused through the judgment of others-Aristotle's fear of disrepute — what is key is the effect of this on one's own sense of self. According to Williams, "[w] hat arouses shame ... will lower the agent's selfrespect and diminish him in his own eyes." ${ }^{13}$ Therefore the kind of fear of disrepute involved in shame is critical: it must be a fear that ultimately affects one's own sense of self and not just one's instrumental calculations in pursuing various goals.

\footnotetext{
${ }_{11}$ Aristotle, Eudemian Ethics, supra note 9 at 1233b26-30.

12 Bernard Williams, SHAME AND NeCESSITY (1993), at 93.

${ }^{13} \mathrm{Id}$., at 90
} 
Here, too, one must tread carefully in articulating the "sense of self" at stake. The idea is not that shame is simply a feeling of being deficient in some important aspect of one's self. The early Rawls offers an account of shame that is very much like this, where shame indicates the loss of some type of excellence that is connected to one's aims or life plan. ${ }^{14}$ However, in his critique of Rawls, Deigh helpfully points out that an individual can have diminished self-esteem without feeling shame. ${ }^{15}$ To use one of Deigh's examples, we can imagine a promising young tennis player who, upon entering a state tournament and encountering a level of competition not previously experienced, realizes that a career in professional tennis is not realistic. As Deigh argues, "His first defeat need not be humiliating, just convincing. And though he will surely lose some self-esteem, we need not suppose that he feels any shame."16 There is something more to shame than the idea that someone has been exposed as deficient in some aspect of their self.

Conversely, one can feel shame without having diminished self-esteem. Deigh provides the example of Crito and his concern for what the citizens of Athens will think for failing to deter Socrates. As Deigh argues,

though Crito is in the end convinced that Socrates' course is the right one and knows all along that he has done everything one can expect of a friend, we still have, I think, no trouble picturing this good-hearted but thoroughly conventional man feeling ashamed when before some respectable Athenian, who reproaches him for what he believes was cowardice on Crito's part. ${ }^{17}$

Shame in this example is not a result of a judgment that Crito's aims are problematic, or that he does not have the necessary abilities to meet these aims. Instead, it arises out of the deprecatory

\footnotetext{
14 JOHn RAWLS, A THEORY OF JUSTICE (1971), at 386-90. Shame, understood as a "natural" emotion, indicates for us "a loss or absence of the excellences essential to our carrying out our more important associative aims." Moral shame indicates the loss or absence of a particular type of excellence - the virtues that are required and encouraged by our plan of life.

${ }^{15}$ John Deigh, Shame and Self-Esteem: A Critique 93 ETHICS 225 (1983).

${ }^{16} \mathrm{Id}$., at 231 .

${ }^{17} \mathrm{Id}$., at 233.
} 
opinion that Crito imagines the Athenians will have of him. Crito was concerned that Athenians would think that he did not do everything possible to help Socrates when indeed he tried and could not convince Socrates to escape rather than to face death. Crito was therefore concerned about the disjunct between his desire to appear to others as aiding Socrates and his understanding that he would appear in quite a different light. It is this disjunct that accounts for his feeling of shame. Importantly, this disjunct may be present even if Crito himself is fully satisfied with his actions. Therefore it is not his self-regard that is at issue. Similarly, it is not just how others regard him that is at stake. This would be his interest in his reputation. Instead, it is the relationship between how he wants others to see him and how they will in fact see him.

Velleman makes a similar point in discussing the difference between social disapproval and shame. He argues that if some things that have been secret about ourselves, such as our ancestry or income, become exposed and associated with the disapproval of others, this does not in itself lead to shame. Indeed, we have the possibility of responding to such disclosures with humility:

If we humbly admitted to our discreditable ancestry, then our response to real or imagined disapproval of it would amount to no more than a feeling of frank inferiority.

The possibility of responding to denigrating regard with humility shows that the perception of facing such regard is not sufficient for shame. That perception doesn't lead to shame unless it leads to a sense of being compromised in our self-presentation. Humility preempts this sense of being compromised by deflating our pretensions and thereby rendering our self-presentation consistent with the criticism that we face. Feeling humbled is thus an alternative to, and incompatible with, feeling humiliated or ashamed. ${ }^{18}$

The idea here has to do with shame being connected to one's desire to present oneself in a particular way - a desire Velleman, following the work of Erving Goffman, describes in terms of

\footnotetext{
${ }^{18}$ James David Velleman, The Genesis of Shame, 30 PHIL. \& PUB. AfF. 27 (2001), at 42-3.
} 
"self-presentation." ${ }^{19}$ Shame is experienced when there is a disjunct between how one wishes to present oneself to others and the impression conveyed by the information now exposed. In other words, shame follows from a "sense of being compromised in our self-presentation."20

The feeling of shame, therefore, is not triggered by how others view ourselves (this is better understood through the concept of reputation) or how we view ourselves (this is better understood through the concept of self-esteem) but rather by our own negative judgment regarding how we want others to view ourselves. It is a complex form of self-consciousness whereby an individual a) is conscious of being seen as $\mathrm{X}$ and $\mathrm{b}$ ) forms a negative judgment regarding what it is to be seen as $\mathrm{X} .^{21}$ This follows even in cases where the individual does not think of herself as X, for what is important is that she not want to be seen by others in this way, as in the Crito example. This also follows in cases where "being seen as X" is not-from the point of view of the audience - a negative judgment. ${ }^{22}$ For example, Velleman argues that sometimes "[w]e keep something private not because we fear disapproval of them but rather because we fear approval of a sort that we would experience as vulgar or cheap" and would result in a feeling of shame. ${ }^{23}$ My self-presentation can be compromised by approval if I do not want approval of the sort offered. Shame always involves a negative judgment but the negative judgment is that of the individual who feels the shame and not of that individual's audience-I can disapprove of your positive view of me if I consider your opinion contemptible.

With this analysis of shame in hand, we can return to the question of the relationship between privacy and shame with more accuracy. According to the view defended here, a feeling

\footnotetext{
${ }^{19}$ See ERving Goffman, The Presentation of Self in Everyday Life (1959).

${ }^{20}$ Velleman at 42.

${ }^{21}$ See also Gabrielle Taylor, Pride, Shame ANd Guilt: Emotions of Self-AsSESSMENT (1985).

${ }^{22}$ See Williams, at 82 , for a similar point

${ }^{23}$ Velleman, at 43.
} 
of shame results from the exposure of things that conflict with the way in which I want to present myself to others. If one of the functions of privacy is to insulate us from shame or the social pressure that this expresses, then we can gain more precision by an alternate formulation: privacy protects important conditions of self-presentation, or our ability to be seen by others in the way that we want to be seen. ${ }^{24}$

This alternate formulation is still extremely general, and will be filled in further in subsequent sections, but even in this form it is helpful in three respects. The first has to do with displacing the role of social norms in favour of the more complex form of self-consciousness that I have described. Instead of linking privacy to the protection of things that one "ought" to be ashamed of if exposed, the view defended here links privacy to protection from being seen in ways that one does not wish to be seen. How one wishes to be seen and how one "ought" to wish to be seen are separate questions and raise further considerations regarding the relation of one's individual identity to social norms. The point is that these are not central to understanding privacy. This account therefore goes some way to displacing the idea that privacy involves hiding discreditable facts about oneself, as Posner has so prominently argued. ${ }^{25}$ It might indeed involve this at times, but hiding discreditable facts does not capture the essence of privacy. All that is essential is that the privacy violation at issue exposes something that I did not want you to know because it makes you see me in a manner I do not want to be seen. One could stretch the meaning of the term "discreditable" to account for this, in the sense that the exposure discredits

\footnotetext{
${ }^{24}$ As will be outlined more fully below, this is a very different idea of identity that what is usually emphasized by privacy theorists. It is not about protecting choices that are intrinsic to identity (Jean L. Cohen, Is There a Duty of Privacy? Law, Sexual Orientation, and the Construction of Identity, 6 TEX. J. WOMEN \& L. 47 (1996, Aaron J. Rappaport, Beyond Personhood and Autonomy: Moral Theory and the Premises of Privacy, UtAH L. Rev. 441 (2001)); nor is it about the integrity of one's identity (Jonathan Kahn, Privacy as a Legal Principle of Identity Maintenance, 33 Seton Hall L. ReV. 371 (2003)); nor does it refer to the conditions under which society recognizes that an individual's "existence is his own" (Jeffrey H. Reiman, Privacy, Intimacy, and Personhood, 6 PHIL. \& PUB. AfF. 26 (1976) at 39).

${ }^{25}$ Richard A. Posner, The Right of Privacy, 12 GA. L. REV. 393 (1978);
} 
the identity that I wish to present. However, that is not Posner's meaning as he invokes the more common, and pejorative sense, of "discreditable" linking it to fraud. ${ }^{26}$

The second helpful feature of this account is that it shows why attention to the nature of particular audiences is important; I might not care what one group thinks of me, but I might care a great deal about another. Take, for example, the well-known case of the former child-prodigy William Sidis. ${ }^{27}$ As an adult he tried to renounce his prodigy status, hiding much of his former life from his adult friends and colleagues, and trying to live a life of relative obscurity. An article published in the New Yorker identified Sidis and had the double effect of informing the general public of what had happened to the prodigy and informing Sidis' current friends and colleagues about his past. Sidis sued for invasion of privacy. From the perspective of the public, the article made him look like a failure - a genius who was so unsuccessful in life that he lived like a recluse in a poor section of town. However it is not clear that Sidis cared about the general public so much as he cared about his ability to live his life free of the burdens of being labeled a prodigy. He did not want colleagues to know, not because he was concerned that they would think he was a failure but because he was concerned that they would no longer let him work as an adding machine operator but would instead expect him to live up to his genius potential. ${ }^{28} \mathrm{He}$ wanted the people he was currently interacting with to treat him as if he were ordinary and being exposed as a former child prodigy prevented this. Reinventing oneself is not necessarily a matter of hiding a discreditable past. Moreover, we do not need to think that Sidis felt humiliated by the exposure in order to identify it as a privacy violation.

\footnotetext{
${ }^{26}$ Richard A. Posner, The Economics of Privacy AEA PAPERS AND PROCEEDINGS 405 (1981) at 406.

${ }^{27}$ Sidis v. F-R Pub. Corp., 113 F.2d 806 (2d Cir. 1940).

${ }^{28}$ This comes out more clearly in Sidis' biography than in the case itself. See Amy WALLACE, ThE Prodigy (1st ed. 1986).
} 
Third, in highlighting the identity interest that underpins privacy norms, this analysis can also help us understand the difference between thinking that exposure is acceptable because there is no privacy interest at stake and exposure is acceptable because there is an important interest that justifies a violation of privacy. To explain what I mean, consider the following passage from Thomas Nagel's analysis of privacy:

What is allowed to become public and what is kept private in any given transaction will depend on what needs to be taken into collective consideration for the purposes of the transaction and what would, on the contrary, disrupts it if introduced into the public space. That doesn't mean that nothing will become public that is a potential source of conflict, because it is the purpose of many transactions to allow conflicts to surface so that they can be dealt with and either collectively resolved or revealed as unresolvable. But if the conventions of reticence are well designed, material will be excluded if the demand for a collective or public reaction to it would interfere with the purpose of the encounter. $^{29}$

Nagel's focus is on the demands of presenting an acceptable public face and so is broadly compatible with the account of shame I have outlined here. However, because he uses this to focus on the social norms of acceptable public expression he sees one of the chief functions of privacy norms as allowing "people to interact peacefully in public" ${ }^{30}$ But suppose that I do not want to expose aspects of my family life and marital relations to others because of the way in which it would compromise my self-presentation. We might nonetheless think that, in the context of contested divorce proceedings in a court of law, that these details must be exposed so that the court can come to a fair resolution of the dispute in accordance with the law. This information becomes a matter of "public" record. According to Nagel's analysis, we cannot call this private information because it needs to be taken into "collective consideration for the purposes of the transaction". In contrast, according to my analysis this is private information

\footnotetext{
${ }^{29}$ Thomas Nagel, Concealment and Exposure, 27 PHIL. \& PUB. AfF. 3 (1998) at 12.

${ }^{30} \mathrm{Id}$., at 5 . Nagel also has a view of privacy as protecting "inner freedom from the stifling effect of the demands of face" (at 23). This connects to accounts of privacy that emphasize privacy as a state of withdrawal. See discussion infra p. 28ff.
} 
because it is information that compromises my self-presentation and its exposure therefore violates privacy. However, considerations that go to maintaining the purposes of the transaction — here a fair and public trial—justify this violation of privacy. In this way, the "publicness" of public records is the conclusion of an analysis that can nonetheless start with acknowledging the privacy interests attaching to some of the information contained in such records but which must balance these privacy interests against other important values. ${ }^{31}$

In sum, an analysis of shame shows us that the protection of the conditions of selfpresentation is one of the central functions of privacy. In turn, this can show us why privacy is not necessarily bound up with ideas of discreditable facts, that general ideas of exposure and "publication" miss the importance of the particulars of audience to one's self-presentation, and that a focus on identity can help distinguish the central interest that privacy norms protect from other interests that might justify violations of privacy.

\section{The Social Aspects of Identity}

In order to gain more precision regarding the relationship between privacy norms and identity, we require a more detailed understanding of the social aspects of identity. The previous discussion indicated that how you feel about what others think of you is what is centrally at stake in the phenomenon of shame. This, in turn, points to the need to understand how individuals negotiate their self-presentation in light of this reflexive concern for how they appear to others. What I want to do in this section is outline the different ways in which this process is "social".

\footnotetext{
${ }^{31}$ It is important to keep these ideas distinct, as some uses of such public records might exceed the scope of the justification for the exposure of the information and so amount to a violation of privacy that is no longer justified. For an extended discussion of this issue see Lisa M. Austin, Privacy and the Question of Technology 22 LAW \& PHIL. 119 (2003).
} 
One of these ways is immediately apparent—what others think about you can be thought of as your social identity. Concern for how you appear to others is therefore a concern for your social identity. In the next section I will outline Erving Goffman's "dramaturgical" account of the self in order to highlight what I take to be several further important features of what I am calling the social aspects of identity. In the subsequent sections I will then show how this contrasts with other ideas of identity such as "self-revelation" and "self-determination" and how these contrasts can illuminate the limitations of many existing accounts of privacy.

\section{(a) Goffman's Account of Self-Presentation}

In his now classic text The Presentation of Self in Everyday Life ${ }^{32}$, Erving Goffman argues that individuals "present" themselves in social interactions and that the self is really the "performed character" that emerges from this presentation. ${ }^{33}$ The self turns out to be a "collaborative manufacture," dependent for its emergence on a number of social structures and the roles played by other people. ${ }^{34} \mathrm{He}$ writes:

[I]n fact these means are often bolted down in social establishments. There will be a back region with its tools for shaping the body, and a front region with its fixed props. There will be a team of persons whose activity on stage in conjunction with available props will constitute the scene from which the performed character's self will emerge, and another team, the audience, whose interpretive activity will be necessary for this emergence. The self is a product of all these arrangements, and in all of its parts bears the marks of this genesis. ${ }^{35}$

\footnotetext{
${ }^{32}$ Erving Goffman, The Presentation of Self in Everyday Life (1959).

${ }^{33} I d$., at 253 .

${ }^{34} I d$.

${ }^{35} \mathrm{Id}$.
} 
We can see here several themes that I will argue are important, including the role of the audience, the presence of other people (team members), and the social equipment (props, roles), that help to constitute the self who is performed.

Goffman's account of the self has been criticized in a number of different ways, and although much of this is not relevant to the use that I want to make of him, several concerns in relation to the idea of individual agency are worth noting. ${ }^{36}$ One important criticism is that Goffman overemphasized the ways in which individuals act in the presence of others in order to elicit certain reactions from them. This criticism takes many forms, including that it is an overly manipulative view of individuals and that it does not account for other grounds of interaction, including morality and rationality. That is, people have many reasons for acting the way they do in the presence of others and only some of these connect to the desire to elicit particular reactions from their audience. Another important criticism - in some tension with the first mentioned--is that Goffman's view of the self ultimately becomes too social, and does not secure enough of a place for individual agency in its "collaborative manufacture". I propose to side-step these concerns by arguing that we can take a number of his insights regarding the social dimensions of identity and remain entirely agnostic about how this relates to other dimensions of agency.

Our social identity, or how others see us, is usually discussed in terms of one's reputation. Everyone has an interest in their reputation. We do not necessarily have to understand this in instrumentalist terms, as important because of how it helps us to further our own goals.

\footnotetext{
${ }^{36}$ See Goffman's Legacy (A. Javier Treviño ed., 2003); PhILIP MANNING, ERVING GofFMAN AND MODERN Sociology (1992); Thomas G. Miller, Goffman, Positivism and the Self, 16 PHIL. Soc. SCI. 177 (1986); Gregory W.H. Smith, Enacted Others: Specifying Goffman's Phenomenological Omissions and Sociological Accomplishments, 28 HUMAN STUD. 397 (2005).
} 
Charles Taylor connects one's reputation to the idea of dignity and suggests that it is one of the three axes of moral thinking, present to some degree or another in every culture. ${ }^{37}$ He argues:

Our 'dignity', in the particular sense I am using it here, is our sense of ourselves as commanding (attitudinal) respect. The issue of what one's dignity consists in is no more avoidable than those of why we ought to respect others' rights or what makes a full life, however much a naturalist philosophy might mislead us into thinking of this as another domain of mere 'gut' reactions, similar to those of baboons establishing their hierarchy. And in this case, its unavoidability ought to be the more obvious in that our dignity is so much woven into our very comportment. The very way we walk, move, gesture, speak is shaped from the earliest moments by our awareness that we appear before others, that we stand in public space, and that this space is potentially one of respect or contempt, of pride or shame. ${ }^{38}$

My sense of myself in relation to the views of others (my social identity) forms the basis of my dignity. And this connects it to the idea of self-presentation in the following way. Selfpresentation refers to the way we want to be seen by others and how we act so that we are seen in this way. It shows us the active role we play in relation to constituting our social identity and thereby also protecting our dignity by seeking to command the respect of those whose respect we value. ${ }^{39}$ This is perfectly compatible with a variety of accounts of other aspects of the self, including the idea that such dignitary reasons for action form only one part of our motivations for action, that other important motivations for action can include rationality and morality, and also that these can be related in a variety of complex ways.

With this in mind, I want to argue that Goffman's views regarding the performative nature of the self illuminate these social aspects of our identity in a manner that is extremely helpful for privacy discussions. Before outlining how it is helpful for privacy discussions, we need to get clear on several key aspects of his account, including the discrediting of

\footnotetext{
${ }^{37}$ Charles Taylor, Sources of the Self : The Making of The Modern Identity (1989) at 15-16; The other two axes are "our sense of respect for an obligations to others" and "our understandings of what makes a full life". ${ }^{38} I d$.

${ }^{39}$ In this I agree with Bloustein that privacy protects dignity. See Edward J. Bloustein, Privacy as an Aspect of Human Dignity: An Answer to Dean Prosser, 39 N.Y.U. L. REV. 962 (1964).
} 
performances, the role of others in the performance, and the role of props and equipment in the performance.

The core of Goffman's position is the idea that in social interactions individuals "present" themselves to others and the core concern regarding such performances is "whether [they] will be credited or discredited." ${ }^{, 40}$ A performance is discredited where something disrupts the definition of the situation that is being presented by calling the terms of the performance into doubt. Note Goffman's description of what happens when “disruptive events” occur:

the interaction itself may come to a confused and embarrassed halt. Some of the assumptions upon which the responses of the participants had been predicated become untenable, and the participants find themselves lodged in an interaction for which the situation has been wrongly defined and is now no longer defined. At such moments the individual whose presentation has been discredited may feel ashamed while the others present may feel hostile, and all the participants may come to feel ill at ease, nonplussed, out of countenance, embarrassed[.] $]^{41}$

Goffman's account of disruptions in self-presentation, therefore, is consistent with the account just offered of the relationship between shame and self-presentation-events that discredit a performance cause the disjunct between how one would like to appear and how you actually appear that can lead to shame.

To understand both this idea of self-presentation and the ways in which it may be discredited, one needs to appreciate the social and interactive nature of Goffman's account. The most important aspect of the social dynamic of identity for Goffman is the idea of an audience. Individuals do not present themselves, or "perform," in a vacuum but to other people. Who these others are is important, for through self-presentation a person will seek to define a situation in

\footnotetext{
${ }^{40}$ Goffman, at 253 .

${ }^{41} I d$., at 12 .
} 
order to attempt to control others' "responsive treatment of him." ${ }^{42}$ Sometimes the location of performance is more important than the specific audience, as when an individual performer wants to "give the appearance that his activity in the region maintains and embodies certain standards" of that region. ${ }^{43}$ For example, a law professor might dress in a particular way because they think that is how law professors in a particular setting should comport themselves, and not have a specific audience in mind. But this is still a performance to a generalized audience in that region and is for the purpose of appearing before that generalized audience in a particular way.

Audience segregation is the aspect of Goffman's work most often taken up in privacy discussions although usually it is through his distinction between a "front and back region" where the back region is where the performance is relaxed and elements of it constructed. ${ }^{44}$ However, many discussions of Gofffman's back region ignore the importance he also places on "front region control." Outsiders - understood as anyone who is not part of the team of performers - can disrupt a performance through intruding in the back region. But outsidersunderstood as anyone who is not part of the intended audience — can also disrupt the front region where the performance takes place. ${ }^{45}$ As Goffman argues,

Incapacity to maintain this control leaves the performer in a position of not knowing what character he will have to project from one moment to the next, making it difficult for him to effect a dramaturgical success in any one of the them. ${ }^{46}$

Indeed, Goffman emphasizes audience segregation as that which enables individuals to play an idealized role: "by audience segregation the individual ensures that those before whom he plays

\footnotetext{
${ }^{42} I d$., at 3 .

${ }^{43} I d$., at 107.

${ }^{44} I d$., at 112 .

${ }^{45} I d$., at 135 .

${ }^{46} I d$., at 137.
} 
one of his parts will not be the same individuals before whom he plays a different part in another setting., ${ }^{, 47}$

Information control is also important. Sometimes this depends upon cultivating particular skills, like controlling inadvertent facial expressions. Goffman argues that an individual's expressive behavior consists in both those aspects that are relatively easy to control, such as statements, and those that are not easy to control, which he calls "expressions one gives off.",48 But information control also means that "the audience must not acquire destructive information about the situation that is being defined for them. ${ }^{, 49}$ Information control is therefore an idea that also depends upon the idea of audience and the need to keep some information away from the intended audience in order to avoid discrediting a performance. I propose to therefore fold information control into a general concern for audience segregation in the rest of this discussion.

Audience segregation also has a social aspect in that it depends in part on audience participation. Goffman is at pains to stress how the audience itself is part of an "interactional modus vivendi" where the audience responds to the individual and seeks to avoid an open contradiction of the way that the individual seeks to define the situation. ${ }^{50}$ The audience does so through various forms of "tact" which include ways in which audiences themselves seek to uphold audience segregation:

The audience can see a great saving of time and emotional energy in the right to treat the performer at occupational face value, as if the performer were all and only what his uniform claimed him to be. Urban life would become unbearably sticky for some if every

\footnotetext{
${ }^{47} I d$., at 49 .

${ }^{48} I d$., at 7.

${ }^{49} I d$., at 141.

${ }^{50} I d$., at.9.
} 
contact between two individuals entailed a sharing of personal trials, worries, and secrets. 51

Therefore audience segregation is not something that works in one direction - as protecting the performative intentions of the individual performer or team — but also can be imposed on a performance by the audience itself and their expectations in relation to the performance.

The idea of audience expectations points us back to another social aspect of one's identity and that is the roles available to a performer. As Goffman is at pains to stress, social interaction involves performers seeking to define a situation within an intersubjective interactional order. In addition to relying on team members and audience participation to secure a credible performance, an individual performer must rely upon already existing social roles in order to define a situation that the audience will understand and accept. For example, Goffman discusses the "front" of an individual performance as "that part... which regularly functions in a general and fixed fashion to define the situation for those who observe the performance." ${ }^{, 2}$ An audience expects coherence between the elements of setting, appearance, and manner of the performer for a successful performance. Moreover, these fronts are not personal to the performer but both participate in, and reinforce, an existing set of socially established fronts that give rise to "stereotyped expectations" on the part of the audience. ${ }^{53}$ This aspect of molding one's performance to the "understanding and expectations of the society in which it is presented" also leads individuals to "incorporate and exemplify the officially accredited values of the society" and downplay actions inconsistent with these values. ${ }^{54}$ One cannot get away from these elements, for the very point of one's social identity is to be seen by others in a particular way. As

\footnotetext{
${ }^{51} \mathrm{Id}$., at 49 .

$52 \mathrm{Id}$., at 22 .

${ }^{53} \mathrm{Id}$., at 27.

${ }^{54} I d$., at $35,41$.
} 
Goffman writes, "[t]o be a given kind of person, then, is not merely to possess the required attributes, but also to sustain the standards of conduct and appearance that one's social grouping attaches thereto." 55

In sum, the central aspects of Goffman's "dramaturgical” account of the self are the following: that individuals perform their identity to an audience with the intention of eliciting a particular response, that the audience participates in this performance, that the performance depends on the activities of team members as well as the social equipment of available social roles and norms that help to define the performance, and that the related requirements of audience segregation and information control are needed to sustain the performance.

In the following section I will use these elements of Goffman's account to examine, and critique, two leading accounts of privacy — control-based accounts and limited access accounts. What I will argue is that their deficiencies as accounts of privacy are really deficiencies in the account identity that, I claim, implicitly informs them. What they are missing is an appreciation of the social dynamics of self-presentation. ${ }^{56}$

\section{(b) Privacy and Questions of Identity}

\footnotetext{
${ }^{55} \mathrm{Id}$., at 75 .

${ }^{56}$ See also Valerie Steeves, Reclaiming the Social Value of Privacy.pdf, LESSONS From THE IDENTITY TRAIL: ANONYMity, PRiVACY AND IdENTITY In A NETwORKED Society 191(Ian Kerr, Valerie Steeves and Carole Lucock, eds. 2009) for a more interactional and social account of privacy. Brian C. Murchison discusses the American public disclosure action in terms of the "liberty to develop character through close, dialogic relationships with others": Brian C. Murchison, Revisiting the American Public Disclosure Action, in NEW DIMENSIONS IN PRIVACY LAW 55 (Andrew Kenyon and Megan Richardson, eds., 2006). Most privacy scholarship instead adopts a model of identity that I refer to in this essay as self-determination.
} 
There are two dominant theoretical approaches to defining privacy: 1) control-based accounts, and 2) limited-access accounts. While there are many different versions of both, the most influential control-based account is Alan Westin's in his book Privacy and Freedom, and the most influential limited-access account is Ruth Gavison's in her article, "Privacy and the Limits of Law. ${ }^{, 57}$ I will discuss each in turn and show how an account of the relationship between privacy and self-presentation highlights the limitations of both approaches.

In Privacy and Freedom, Alan Westin defines privacy is as follows:

Privacy is the claim of individuals, groups, or institutions to determine for themselves when, how, and to what extent information about them is communicated to others. Viewed in terms of the relation of the individual to social participation, privacy is the voluntary and temporary withdrawal of a person from the general society through physical or psychological means, either in a state of solitude or small-group intimacy or, when among larger groups, in a condition of anonymity or reserve. The individual's desire for privacy is never absolute, since participation in society is an equally powerful desire. Thus each individual is continually engaged in a personal adjustment process in which he balances the desire for privacy with the desire for disclosure and communication of himself to others, in light of the environmental conditions and social norms set by the society in which he lives. The individual does so in the face of pressures from the curiosity of others and from the processes of surveillance that every society sets in order to enforce its social norms. ${ }^{58}$

On this view of privacy, then, individuals negotiate the boundary between social withdrawal and social interaction. Westin's use of "privacy" actually plays two roles in this passage. The first is to equate it with a claim of control in relation to negotiating this boundary between withdrawal and interaction. The second is to equate it with the state of withdrawal (for Westin, voluntary) from society. Setting aside the potential overlaps between this second use (withdrawal) and Gavison's limited access approach, both uses of privacy connect with a particular views of identity. Control over information permits individuals to choose what to reveal to others, which

\footnotetext{
${ }^{57}$ Alan F Westin, Privacy And Freedom (1967); Ruth Gavison, Privacy and the Limits of Law, 89 Yale L. J. $421(1980)$.

${ }^{58}$ Westin, at 7.
} 
is how the boundary between social withdrawal and social interaction is negotiated. Westin connects the function of privacy with personal autonomy, which he understands as the protection of a "core self." He describes this core self in terms of "a series of concentric circles" with the inner circle sheltering "ultimate secrets" to which nobody is normally admitted out to "the outer circles of casual conversation and physical expression that are open to all observers." ${ }^{\circ 9}$ Another function of privacy is "emotional release" and here too a certain idea of the self emerges. Individuals need a place of relaxation from playing social roles, a moment "off-stage" to be "himself.",60 Privacy also makes possible "self-evaluation" in which individuals withdraw from society in order "to integrate [their] experiences into a meaningful pattern and to exert [their] individuality on events.",61

Westin's understandings of identity here are better labeled as "self-revelation" and "selfdetermination" rather than "self-presentation." Let me start with self-revelation. Self-revelation depends upon an idea of a self that is formed prior to any particular social relation, with the individual (who "possesses" this self) determining what to reveal and to whom. While this self might still be understood to be formed through actions, the grounds of self-constitution are not necessarily social as in Goffman's interactional model. ${ }^{62}$ Indeed, this self is most "himself" when in a state of social withdrawal, and is selectively revealed to others in the face of pressure to conform to social norms. Other people exert pressure on individuals to conform to social norms, but are otherwise not involved in the process of identity formation. Given this, Westin's characterization of privacy as control over personal information is understandable. We could say

\footnotetext{
${ }^{59} I d$., at 33. Privacy also permits emotional release and protects communication. See 34-39.

${ }^{60} \mathrm{Id}$., at 35 . He cites Goffman for this, but Goffman had no such view of a core self.

${ }^{61} \mathrm{Id}$., at 36.

${ }^{62}$ Indeed, many influential accounts root the self in rational agency See, e.g., CHRISTINE M KORSGAARD, SELFCONSTITUTION : AGENCY, IDENTITY, AND INTEGRITY (2009).
} 
that for Westin, what is central is that the individual control which information is revealed to which audience.

Although Westin's account echoes some of the elements of Goffman's concerns regarding audience segregation and information control, it remains crucially different. If we shift to an understanding of social identity in terms of self-presentation then Westin's focus on individual control requires displacement in favour of a more multi-faceted view of protecting the conditions of identity. On Goffman's account both the failure of information control and the failure of audience segregation can lead to a failure of self-presentation although the presence of both does not ensure the success of any given "performance." But because the social self emerges through social interaction, social conventions and the actions of the audience play a large role in maintaining the conditions necessary for self-presentation, and show why an emphasis on individual control is misplaced. For example, on Goffman's account audience practices of tact can save a performance that is disrupted by the failure of information control. Suppose that I find your diary lying open on the sidewalk where it fell out of your bag. I can choose to avert my eyes, close the book and even seek to give it back to you, all of which protects your self-presentation without needing to also suppose that this must be understood in terms of your control over your self-presentation.

Or suppose instead that you act in a manner so as to reveal everything to everyone. On a control-based account of privacy, this might be psychologically unwise but does not count as a violation of privacy despite the fact that most people would think that such an individual has no sense of privacy. Goffman, however, stresses the social aspects of self-presentation that can help 
us make sense of this example as indeed involving a loss of privacy despite not involving the violation of individual control. Self-presentation takes place within a social context of team members and props that have social meaning. In other words, the definition of a situation is not entirely within the control of an individual. Moreover, according to Goffman, the audience to whom one presents oneself within this social context participates in an interactional modus vivendi, seeking also to uphold effective audience segregation and information control. This is how we can consistently say that the individual has chosen to present herself in a particular way but that this presentation nonetheless flouts privacy norms - the individual is engaged in a performance that does not respect general social expectations regarding audience segregation and information control in that setting. ${ }^{63}$

This general point regarding the role of the audience and broader social structures means that the scope of individual agency in relation to one's social identity is not necessarily as strong as it is on other accounts of identity, like self-determination accounts. The social self is not an individual achievement, free of the influence of others, who then goes on to interact with others in a manner that is more or less "authentic". This can actually help us to understand Westin's emphasis on social withdrawal as a means of constituting oneself through reflection and a relaxation of one's social mask. I want to suggest that this is in fact a very particular expression of the liberal ideal of self-determination.

By self-determination I mean to refer to accounts of a liberal self — and there are many different versions - that emphasize the ways in which an individual must determine the grounds of her identity free from the undue influence of others and prevailing social norms. This might

\footnotetext{
${ }^{63}$ See Robert Post, The Legal Regulation of Gossip: Backyard Chatter and the Mass Media" in Good GossiP 6 (Robert F. Goodman \& Aaron Ben-Ze'ev, eds., 1994).
} 
seem incompatible with self-presentation but I think that is better seen as a view that seeks to deemphasize the importance of what-we-think-about-how-other people-think-about-us in order to affirm the importance of self-constitution. For example, one could think of John Stuart Mill in this way. Although he was acutely sensitive to social coercion, he took aim at social coercion that resulted in actual harm-for e.g., when someone was deprived of their livelihood because of the social stigma resulting from holding unpopular views. Social censure that simply leads to an individual being ill-thought of was not such a harm. ${ }^{64}$ The development of individuality and diversity is secured, for him, through freedom of expression and a vigorous marketplace of ideas. Others have emphasized the need for private space in order to have a place free of the influence of others in order to engage in reflection and experimentation that is part of this project of selfconstitution. ${ }^{65}$ The point is that accounts of identity that I am labelling self-determination are more focused on insulating individuals from undue social influence than on protecting the integrity of social interaction. It is not that they deny the nature of one's social identity, or how this aspect of social interaction might function, but their emphasis is instead on the idea of one's true and authentic self and how this might be self-created rather than socially imposed. Similarly, although Goffman's account of self-presentation does not deny the role of individual agency in the performance of the self, he accepts that the social nature of this performance means that it is compatible with a great deal of social conformity. Locating the ways in which this conformity might be resisted is important, but not necessary to understanding how the basic dynamic of selfpresentation operates.

\footnotetext{
${ }^{64}$ J.S. MiLl, ON LIBERTY (Elizabeth Rapaport, ed., 1978) (1859) at 30-31.

${ }^{65}$ See Jeffrey H. Reiman, Driving to the Panopticon: A Philosophical Exploration of the Risks to Privacy Posed by the Highway Technology of the Future, 11 SANTA Clara COMPUTER \& HiGH TECH. L.J. 27 (1995).
} 
Westin's control-based account of privacy, therefore, must be understood to take the expression it does through the influence of ideas of self-revelation and self-determination. What the account does not express well is the idea of self-presentation and the role it gives to audience participation and social norms and roles. This deprives control-based accounts of the ability to understand why it might be intelligible to say that someone has chosen to give up their privacy, or that their privacy has been respected even though they lack control over information.

Other accounts of privacy emphasize the relationship between privacy and solitude or some idea of retreat from others, independently of ideas of individual control. This is at the basis of the so-called "limited access" accounts of privacy, where a state of privacy ensues when others have limited access to you, whether in terms of information or physical proximity. ${ }^{66}$ Privacy, on such a view, is a state of social withdrawal. Indeed, one has perfect privacy when one is alone and any revelation of information about oneself — even if freely chosen — necessarily involves a loss of privacy. The key is to then decide which losses of privacy are ones that we should care about. This emphasis on privacy as a state of withdrawal, rather than on the means of controlling the terms of revelation as in control-based accounts, means that limited access accounts are not overly dependent on the idea of individual control--there may be many different ways of ensuring limited access in areas that we care about.

How then do we decide which losses of privacy (involving increased access to individuals) are ones that we care about? Many have argued that one of the values of this ability to withdraw from others is that it ensures our capacity to engage in social experimentation and to forge an authentic self. Similar to Westin's concern to protect an "off-stage" area of repose and

\footnotetext{
${ }^{66}$ Prominent proponents of this view include Ruth Gavison, JUdith WAGNER DECEW, IN PURSUIT OF PrIVACY : LaW, Ethics, AND the Rise of TeChnology (1997); ANita L Allen, UnEAsy ACCess : Privacy for Women in A FREE SOCIETY (1988).
} 
self-reflection, the idea underpinning the value of social withdrawal is that we sometimes need to be free from observation in order to engage in unpopular activities as well as self-reflection, for we would feel inhibited if observed. ${ }^{67}$ Limited access accounts of privacy therefore are strongly informed by self-determination models of identity and their emphasis on authenticity and experimentation. ${ }^{68}$

Goffman's account of self-presentation can accept the impulse for social withdrawal, but it would recast the concern within a social dynamic that is divorced from a concern for authenticity. On his account, we could say that in order to avoid being seen in a certain way by a particular audience, an individual may avoid engaging in certain actions. She may in fact feel that these actions are important, interesting, and desirable but if a particular audience would view them differently, and she does not want to be viewed in that way, then she may feel inhibited. While this may look like a disjunct between her "authentic" self and the self she wants to reveal to others, we do not need to make any claims regarding authenticity to explain her predicament. All that is necessary is that there is a difference between how an individual feels about herself (in relation to an activity) and how an individual feels about how others would view herself (in relation to an activity). Nor does the "off-stage" area of one's life need to be thought of in terms of solitude or retreat. ${ }^{69}$ For one thing, understood in Goffman's terms, the "backstage" of the performance is a social place inhabited by team members and props ${ }^{70}$ But more importantly, the point of the backstage within an account of self-presentation is not to determine some sense of your true self independent of social interaction but who you want to present yourself as to a

\footnotetext{
${ }^{67}$ See Gavison, at 451 ; Reiman, at 42.

${ }^{68}$ Julie Cohen draws upon this set of values to articulate what is at stake where surveillance is known. See Julie Cohen, Privacy, Visibility, Transparency, and Exposure, 75 U. CHIC. L. REV. 181 (2008) at 194.

${ }^{69}$ Note that the tradition of solitude was originally about a different kind of relation-one's relation with God

${ }^{70}$ For a defence of internet privacy in terms of providing "space for individual deliberations about identity" within a self-determination model of identity see Paul M. Schwartz, Privacy and Democracy in Cyberspace, 52 VAND. L. REv. 1609 (1999) at 53.
} 
particular audience, with some view of how you want them to interact with you. Therefore the idea of social withdrawal can be recast in terms of withdrawal from particular audiences and so need not be understood as involving solitude, or a realm free of the influence of others. In this way, self-presentation can accommodate some of the insights of the limited access accounts of privacy — and its animating ideals of self-determination — while preserving the sense that privacy norms protect the terms of social interaction and not social withdrawal.

This is important, as one of the criticisms of limited access accounts of privacy is that they do not properly appreciate the centrality of choice or even control in our understandings of privacy. For example. Rössler argues that “[a] crevasse into which I have fallen is clearly not 'private', even though it does comply with the condition of 'inaccessibility' ... If a state of isolation, seclusion or secrecy is enforced and not freely chosen, in other words if the person in question has no control over it, then one would not describe it as "private'.,71 Because limited access accounts ignore the dynamics of social identity they miss the sense in which privacy norms are connected to, and protective of, the very active and interactional sense of identity formation which does have elements of choice and control, as already discussed. One might be alone in a crevasse, but this has little to do with self-presentation. ${ }^{72}$

\section{(c) The Contextual Nature of Privacy}

One of the main attacks on both control-based accounts and limited-access accounts of privacy has come from theorists who, in different ways, point to the deeply contextual nature of privacy

\footnotetext{
${ }^{71}$ Rossler, at 7.

${ }^{72}$ Some theorists, seeking to address these interactional elements of identity formation criticize the limits of the language of privacy because of its traditional twinning with ideas of withdrawal. See generally David J. Phillips, From Privacy to Visibility: Context, Identity, and Power in Ubiquitous Computing Environments, 23 Soc. TEXT 95 (2005).
} 
norms. For example, Solove claims that privacy is better understood as a series of concerns that bear a "family resemblance" to one another but defy conceptual coherence. ${ }^{73}$ Nissenbaum provides an account of privacy as "contextual integrity" ${ }^{74}$ Privacy norms, she argues, should be understood as norms about the "information flow" that is appropriate in different contexts. Whitman argues that privacy norms are culturally specific, with Europeans focused on its dignitary aspects and Americans focused on liberty from the state. ${ }^{75}$ All of these accounts enrich our understanding of how we draw the line between public and private. However, Nissenbaum and Solove's work points to the need to eschew a simple public/private divide whereas Whitman's work points to why the existing divide is so deeply drawn. All are different from the framework of self-presentation that I have outlined.

The public/private divide that animates many privacy debates has deep roots in ideas quite different from self-presentation. I argued earlier that we can act on the basis of many different types of motivations, including morality and rationality, and that a concern for how we appear to others is only one such motivation. I also pointed to Taylor's argument that this was tied to our sense of dignity, which is but one of the three axes of moral thinking he claims are present in every culture but to different degrees and in different iterations (the other two being idea of obligations to others and ideas of human flourishing). ${ }^{76}$ What Whitman's work does is indicate how these other axes can also generate ideas of privacy which are sometimes at odds with ideas of privacy that connect instead with dignity. In particular, Whitman points to the centrality of ideas of liberty in American cultural views of privacy. I would like to recast this "cultural" argument in terms of political ideas of the liberal state and show how it leads to an

\footnotetext{
${ }^{73}$ DANIEL J. SOLOVE, Understanding PRIVACy (2008).

${ }^{74}$ Helen Nissenbaum, Privacy in Context : TeChnology, Policy, and the Integrity of Social Life (2010).

75 James Q Whitman, The Two Western Cultures of Privacy: Dignity Versus Liberty, 113 YALE L. J. 1151 (2004).

${ }^{76}$ Taylor, at 15-16.
} 
understanding of privacy that is very much connected to the kinds of activities that take place behind closed curtains in one's home. Then I will show how other contextual accounts of privacy have tried to highlight the limits of such a view and how the framework of self-presentation can provide such projects with more analytic rigour.

Liberal theory in its many guises seeks to define a private sphere within which the state may not interfere with an individual's pursuit of various ends. The public/private divide, however cast in its particularities, demarcates a line between the legitimate exercise of the state's coercive authority on one side and protected individual liberty on the other. It is this sense of the private as a sphere free from state interference that is responsible for what may sometimes appear to be peculiarities in the use of the language of privacy and, in particular, its close alignment with the value of autonomy. ${ }^{77}$

The home is "private" in a number of ways that intersect with ideas of liberty. One set of ideas is that the activities that take place within the home are private in the sense that they are not, or should not be, open to state interference. Feminists have often contested this sense of the home as private, arguing that it has shielded men from accountability for their actions within the home, including domestic violence, but have also sought to re-imagine a less oppressive sense of what privacy in the home might mean. ${ }^{78}$ The home is also private in the sense of being (at least paradigmatically) private property. Property rights are a key element of most traditional liberal

\footnotetext{
${ }^{77}$ For example, American jurisprudence holds that the right to privacy includes a right to decisional autonomy. See Anita L. Allen, Privacy in American Law, in Privacies: PhilosophiCal Evaluations, 19-39(Beate Rössler, ed., 2004). Canadian constitutional jurisprudence has affirmed that privacy "is at the heart of liberty in a modern state." R. v. Dyment, [1988] 2 S.C.R. 417 981, citing Alan F. Westin, PrivaCy AND FreEdom (1970) at 349-50. ${ }^{78}$ Ruth Gavison, Feminism and the Public/Private Distinction, 45 STAN. L. REV. 1 (1992); Iris Marion Young, A Room of One's Own: Old Age, Extended Care, and Privacy, in Privacies: Philosophical Evaluations, 168186(Beate Rössler, ed., 2004).
} 
conceptions of individual liberty and also an important way of marking out a boundary against legitimate state interference. ${ }^{79}$

Another set of ideas, which overlaps with property ideas, is the idea that activities within the home are shielded from the view of others. Property rights - in particular the right to exclude others - provides an individual with the ability to control access to her home, permitting her to choose to shield areas of her life from the view of others. ${ }^{80}$ But this sense of privacy can also be invoked when people close their curtains so that their inquisitive neighbours cannot see inside even though they remain on the public sidewalks. Finally, this set of ideas overlaps with the liberal ideal of self-determination, already discussed, where the home plays the role of a place of repose that shields its inhabitants from the influences of the broader social world and enables the project of authentic self-creation.

The close alignment between the American understanding of privacy and ideas of liberty and the home are therefore rooted in a number of liberal ideals involving the idea of the private sphere, the role of private property, and the aspiration to self-determination. This means that when we ask the question "what is private?" the answer has often been some form of: that which is associated with intimate and sensitive activities and relationships such as those affiliated with the family and the home, or those that one would wish to shield from the state. We could say, following Whitman, that the reason for this is that American culture pays relatively little attention to ideas of dignity and so its ideas of privacy must be understood through a very different lens. There is a lot to this idea, but I want to suggest a different view. If we think about dignity in terms of self-presentation then we can see that many of the core ideas of Goffman are

\footnotetext{
${ }^{79}$ See Richard A. Epstein, Design for Liberty: Private Property, Public Administration, AND the Rule of LAW (2011) for a recent defense of this view.

${ }^{80}$ This can also have identity implications. See Lisa M. Austin, Person, Place, or Thing? Property and the Structuring of Social Relations, 60 U.T.L.J. 445 (2010).
} 
perfectly compatible with different cultural iterations. For example, we require some social norms regarding audience segregation in order for self-presentation to be possible but there is no essential content to these norms - they may well indeed revolve around ideas of the boundaries established by the home, especially when these boundaries get reaffirmed through a variety of other cultural and political values. If this is so, then we might not even realize the overlapping nature of what is demanded by self-presentation and what is demanded by other values such as liberty.

We might not notice, that is, until they come apart. And come apart they do in the fact of contemporary information and communications technology. Suddenly privacy intuitions are engaged in the face of practices made possible by such technology, calling into question the use of a public/private dichotomy drawn from this set of ideas about liberty. This is the target of two of the most prominent contextual accounts of privacy — those offered by Solove and Nissenbaum. For example, Solove critiques the over-reliance on paradigms of secrecy that are prevalent in legal thinking about privacy and which lead courts to "find no privacy interest if information is in the public domain, if people are monitored in public, if information is gathered in a public place, if no intimate or embarrassing details are revealed, or if no new data is collected about a person." ${ }^{81}$ A focus on privacy "problems," like those identified in his taxonomy, can show that "problems and harms can emerge in all settings." 82 Nissenbaum emphasizes the multiple contexts in which we find information norms and so denies a simplistic dichotomy between a private and public sphere. Privacy is violated when information practices violate contextual boundaries such as when information collected in one context is used and disclosed in very different context, with different norms of information flow.

\footnotetext{
${ }^{81}$ Solove, at $187-8$.

${ }^{82} \mathrm{Id}$.
} 
I want to claim here that while these theorists are correct in calling into question the traditional liberal private/public divide, they go too far in embracing the contextual nature of privacy norms. The problem is that they lose sight of the dynamic of identity that remains central to an understanding of privacy and, in doing so, loses precision and explanatory power.

For example, Nissenbaum defines contexts as "structured social settings characterized by canonical activities, roles, relationships, power structures, norms (or rules), and internal values (goals, ends, purposes). ${ }^{, 83}$ When thinking about whether information practices are problematic, we start with existing norms and then take into account the moral and political factors potentially affected by a practice, such as "the effects on power structures, implications for justice, fairness, equality, social hierarchy, democracy, and so on" as well as the "values, goals, and ends of the context. ${ }^{\prime 84}$ Privacy is really a conclusion that follows from taking into account an incredibly wide range of factors.

Nissenbaum's insights into contextual integrity can be usefully reframed within an account of self-presentation. Her understanding of contextual boundaries maps onto Goffman's concerns for audience segregation as necessary to maintain the success of a performance. But the self-presentation framework allows us to make other useful distinctions that get run together on Nissenbaum's account, including the basic means of self-presentation, the identity forms or social roles available to us, the value that these roles might have in relation to the broader political culture, the expectations that others have of us in relation to these social roles, and the kinds of values that can override these in different contexts. In other words, self-presentation can

\footnotetext{
${ }^{83}$ Nissenbaum, at 132 .

${ }^{84} \mathrm{Id}$., at 182.
} 
provide an analytic framework for understanding how the different contextual factors at issue relate to one another.

Similarly, a taxonomy of privacy problems like Solove provides is premised on the idea that there is nothing uniting these problems but a family resemblance. Prosser alleged the same thing in relation to the four branches of the American tort of invasion of privacy. ${ }^{85}$ But let us take these four torts and look at them through the lens of self-presentation rather than a different idea of identity. Both publicity given to private facts and intrusion upon seclusion, within a selfpresentation account, involve a failure of audience segregation. Recall that for Goffman, "outsiders" could disrupt the performance through an intrusion on either the front region where the performance is staged to a particular audience or the back region, where aspects of the performance are constructed. Both the false light publicity branch and the appropriation of name or likeness branch address a different kind of disruption of self-presentation. In these classes of case the issue is not audience segregation but the sense in which a particular presentation is selfpresentation. To be portrayed in a false light is like having a performance imputed to you when you were not involved. To have someone appropriate your name is to have them perform as you. Although these different branches all address different problems, they can indeed be usefully united as seeking to protect basic conditions of self-presentation.

Contextual accounts fare better than more traditional accounts of privacy in providing an account of privacy in public. They do so largely by showing how the public/private dichotomy is too simplistic in not accounting for what are in fact multiple social contexts. Goffman's account of self-presentation is very useful in providing more analytic rigor to such accounts. Take the question of anonymity. Anonymity has long been viewed by many privacy scholars as an

${ }^{85}$ William L. Prosser, Privacy, 48 CAL. L. R. 383 (1960). 
example of privacy in "public". ${ }^{86}$ For example, even Alan Westin describes anonymity as one of the four basic states of individual privacy and "occurs when the individual is in public places or performing in public but still seeks, and finds, freedom from identification and surveillance." ${ }^{87}$

Freedom from being identified permits individuals a freedom from social expectations associated with that identity, permitting the individual to "merge into the "situational landscape. ${ }^{88}$ Unless a person "is a well-known celebrity, he does not expect to be personally identified and held to the full rules of behavior and role that would operate if he were known to those observing him." 89 As Westin also notes:

Anonymous relations give rise to what Georg Simmel called the "phenomenon of the stranger," the person who "often received the most surprising openness-confidences which sometimes have the character of a confessional and which would be carefully withheld from a more closely related person." In this aspect of anonymity the individual can express himself freely because he knows the stranger will not continue in his life and that, although the stranger may give an objective response to the questions put to him, he is able to exert no authority or restraint over the individual. ${ }^{90}$

In this way, anonymity functions in the same way as more obvious privacy norms that are tied to the demarcation of a private sphere to which one can withdraw from others.

Despite Westin's insight into anonymity as a state of privacy, his comments remain premised on an idea of interacting in a public place with people who are strangers. Yet the "phenomenon of the stranger" that he adopts from Simmel can also be cast in terms of audience segregation. If your audience is your brother, then the norms of your particular role as a sibling within your family will help to condition the terms of your self-presentation. This can be experienced as inhibiting if, as outlined above, you do not want your brother to see you in a

\footnotetext{
${ }^{86}$ See Lisa M. Austin, The Privacy Interest in Anonymous Blogging, in AMATUER MEDIA: SocIAL, CULTURAL AND Legal PeRsPeCtives (Dan Hunter, Megan Richardson and Ramon Lobato, eds., forthcoming in 2012).

${ }^{87}$ Westin, at 7 and $31 \mathrm{ff}$. The other three basic states are solitude, intimacy and reserve.

${ }^{88} \mathrm{Id}$., at 31 .

${ }^{89} I d$.

${ }^{90}$ Id, at 31-32, citing THE SOCIOLOGY OF GEORG SIMMEL (Kurt Wolff, tr. and ed., 1950) at 402-408.
} 
particular way in a particular context. Moreover, you probably will feel this fairly acutely given that the particular social role of being a sibling means that you will have ongoing social interactions with him. If your audience is instead a stranger then there are a limited number of social roles — and their attendant norms - that are brought to bear in framing the interaction and there is unlikely to be further interactions. In addition, interacting with someone who does not know your name, for example, makes it less likely that what you do or say will travel beyond that context and reach other audiences. The point is that the nature of one's particular audience matters to one's self-presentation and this self-presentation needs to be protected against "outsiders" who are not the intended audience. The phenomenon of the stranger is just a special case of the general interactional framework that Goffman describes in his work on selfpresentation.

Using the idea of audience segregation instead of anonymity provides a more helpful means of thinking about the difference between identifying information — for e.g., something that makes a medical record identifiable information rather than anonymous information such as a patient's name - and information that is about me — for e.g., the actual contents of my medical record. Identifying information can function as the means through which other information is shared. This information is worth protecting as a means of ensuring audience segregation rather than because it itself is to be protected from various audiences. For example, it is clear that a list of names associated with record numbers is not in itself private in the sense of its disclosure in itself compromising my self-presentation. But what that information can do is link a particular medical record with my name - which can result in that information reaching an audience that was not intended nor desired. 


\section{Legal Anxieties about Identity}

So far I have argued that it is important to attend to the idea of shame because it can show us the constitutive relation between privacy and identity. Shame involves the self-consciousness of how one appears to others, and how one feels about this. This points us to the relationship between privacy norms and identity understood in terms of self-presentation. My claim has been that privacy norms enable the conditions of self-presentation and, further, that Goffman's account of self-presentation is helpful in highlighting the social and interactional nature of self-presentation. With this understanding of the relationship between privacy and identity in hand, we can see more clearly that a number of problems with some of the traditional accounts of privacy (privacy as control, privacy as limited access) stem from limitations in the underlying understanding of identity that informs and motivates these accounts. We can also see the ways in which some of the alternative, contextual accounts, of privacy go too far in embracing context and lose sight of the central role of identity in accounting for privacy norms.

In this section I will show how a focus on identity can illuminate some of the problems associated with the question of what kind of legal protection we should give to privacy. My argument here is that privacy actually makes a poor candidate for legal rights and that we should look to a different set of legal ideas to frame the legal protection of privacy. My suggestion for such an alternative paradigm is the language of legality, or the rule of law.

\section{(a) Why not rights?}


I want to suggest that there is a problem with thinking about the legal protection of privacy in terms of legal rights rather than some other set of legal ideas. I want to also suggest that one of the central reasons for this problem is that ideas of identity and ideas of legal rights are in some tension with one another. But, I will argue, we should view this as a productive tension that propels us towards embracing a different legal framework for the protection of privacy.

The basic problem with a legal right to privacy lies in the dilemma of justification. ${ }^{91}$ The idea of legal rights places constraints on our idea of rights because it demands that these rights conform to the kinds of interests that can justify state coercion in their enforcement. These considerations point to the need for an additional step in any account of privacy that purports to be the basis for a legal right to privacy - that step is taking into account the justificatory demands of legal rights more generally.

Traditional liberal accounts of justified coercion focus on ideas of harm and autonomy. But ideas of privacy sit uneasily within such accounts - many purported violations of privacy fall short of the kind of harm or violation of autonomy we find in more traditional legal rights. For example, suppose that you take my photo surreptitiously while I am doing something and I think nobody is watching. I would likely feel that this is an invasion of my privacy and the previous analysis of self-presentation would tell me why: you are an outsider to my intended audience and, further, by taking the photo you make possible the further exposure of my activities to other outsiders. But in taking the photo you have not harmed me in any conventional sense. If you publish the photo it is still unclear what the harm is, unless it is so humiliating as to cause

\footnotetext{
${ }^{91}$ For a full articulation of this argument, see Lisa M Austin, Privacy and Private Law: The Dilemma of Justification, 55 McGILL L.J. 165 (2010).
} 
substantial emotional distress. Even John Stuart Mill, so sensitive to the tyranny of the social sphere, thought that being ill-thought of "ought not to require a very heroic mould" to bear and was not a form of social coercion individuals needed protection from. ${ }^{92}$

Perhaps I instead said, "Well, had I known you were going to take my photo I might have acted differently." But the social "inhibition" that this points to falls far short of coercion. There are lots of ways in which my knowing how you might act or react in a particular situation would cause me to change my own actions - but this is simply part of the social context of action, not in and of itself a violation of autonomy. Even Kant, who found that the "mania for spying on the morals of others" was an "offensive inquisitiveness", thought that such disrespect was a matter for ethics, not law. ${ }^{93}$ A violation of the duty of respect concerns the violator's inner motivation, which for Kant is a matter of the doctrine of virtue and not the doctrine of right.

All of this is to say that there are any number of situations where it makes sense to think that privacy has been violated but where it is surprisingly difficult to identify a clear harm or violation of autonomy that standard accounts of legal rights demand.

Given that legal rights fit most easily within a framework of harm and autonomy, and that privacy concerns are not well articulated within either framework, one would expect this tension to show up in the case law. I think it does. If we look at what courts do we see that they bring the scope of the tort of invasion of privacy into alignment with more standard notions of autonomy and harm. For example, they do this when they keep privacy close to the law of confidentiality or

\footnotetext{
${ }^{92}$ Mill, at 30-31.

${ }^{93}$ IMMANUEL KANT, The Metaphysics OF MoRALS 24 (Mary Gregor, tr. and ed., 1996) (1797).
} 
through insisting on some kind of threshold of harm through the requirement of "offensiveness." In my view, this is not because of an idea of privacy but rather is because of the idea of legal rights and their justification that constrain the scope of legal protection.

This should not be so surprising if privacy norms protect the capacity for selfpresentation, as I have been arguing. Traditional liberal accounts of rights seek to determine what is normative in legal relations by abstracting from identity — various forms of the liberal self have this feature. Both autonomy- and harm-based accounts of legal rights involve ignoring the particulars of identity or social context and viewing the terms of our interaction through the normative lens of formal equality, resting upon abstract individual ideas of autonomy or harm. Indeed, this is the very point — to determine what is normative in human interaction that does not depend upon one's friends and family connections, group membership, physical traits, etc. As Herzog so memorably pointed out, there was, and is, a political function to liberal theory's insistence on abstracting individuals from their social context, one that was meant to empower individuals in the face of exploitative social hierarchies. ${ }^{94}$ The fundamental problem, therefore, is that the traditional language of rights was never meant to capture aspects of identity. If we take Taylor's views regarding the three axes of moral thinking, we can get another perspective on why self-presentation cannot fit itself easily into a framework of rights. Ideas of rights and obligations are what he calls the first axis, which is dominates in the modern West and is, he argues deeply rooted in both ideas of autonomy and ideas of minimizing suffering. ${ }^{95}$ Our accounts of legal rights draw deeply from this tradition but remains distinct from the dignitary concerns that underpin self-presentation. A right to privacy, therefore, sounds in the wrong

\footnotetext{
${ }^{94}$ Don Herzog, As Many as Six Impossible Things before Breakfast, 75 CAL. L. REV. 609 (1987).

${ }^{95}$ Taylor, at $12 \mathrm{ff}$.
} 
register. It will only work when it overlaps some other set of values that do find a home within a framework of autonomy or harm. And this means that a legal right to privacy will only catch what lies at the periphery of privacy — an important role but one that still leaves open the question of what it would mean for law to attend to the center.

All of this suggests that we should think of the legal protection of privacy outside of the framework of liability for rights violations. And, indeed, much of the international community is moving in this direction by rallying around the idea of the need for data protection legislation embodying what have come to be known as "Fair Information Practices."96 Although Fair Information Practices are rapidly becoming the international language of privacy, little attention has been paid to them by privacy theorists who remain focused on both tort law and consitutional law. In the following section I want to show that once we move beyond ideas of legal rights, there are other legal ideas that may be more helpful in understanding why this is a better way of thinking about privacy than through the categories of private law rights.

\section{(b) Alternative Paradigms}

The best way to identify alternatives to a rights-paradigm is to understand how other legal ideas get distorted by being forced into the language of rights. Here I will present three different ideas that stake out alternative ground and suggest the ways in which these ideas can illuminate privacy law. These ideas are H.L.A. Hart's understanding of a legal power, Jeremy Bentham's

\footnotetext{
${ }^{96}$ OeCD, Guidelines on the Protection of Privacy and Transborder Flows of Personal Data, Annex to Recommendation of the Council (23 September 1980). [Hereinafter "OECD Guidelines".] Canada has comprehensive private sector data protection law modelled on Fair Information Practices. See The Personal Information Protection and Electronic Documents Act, S.C. 2000, c.5. Seventy-eight countries now have such private sector legislation: Graham Greenleaf, The Influence of European Data Privacy Standards Outside Europe: Implications for Globalisation of Convention 108, 2 INT'L DATA PRIV. LAW (2012). The United States is an outlier in its preference for sector-specific legislation.
} 
views on expectations, and Lon Fuller's understanding of the principles of legality. There are many aspects of these thinkers' work that is in deep tension with one another and while there may be ways in which to resolve these tensions this is not my focus here. Rather, I present these three ideas as illuminating of the limits of a rights-paradigm in general, and as pointing us towards a more fruitful way of thinking about the legal protection of privacy.

One of the central distinctions that H.L.A. Hart makes in The Concept of Law is the distinction between "power conferring rules" and "coercive orders". ${ }^{97}$ He argues that coercive orders can be understood in terms of actionable wrongs, through ideas of duties and the sanctions imposed through the breach of these duties. ${ }^{98}$ However, such a framework cannot account for laws that do not primarily impose obligations but instead "provide individuals with the facilities for realizing their wishes, by conferring legal powers upon them to create, by certain specified procedures and subject to certain conditions, structures of rights and duties within the coercive framework of law." 99 Such powers include those conferred through the law of contracts and wills but also the many public powers that define the roles of legal officials. The latter-powers that define the roles of legal officials--was, of course, Hart's focus and he said relatively little about private law powers. What he did say consistently is that we cannot view these powers through the lens of the liability that arises when the system fails. Instead, legal powers are integral to "the diverse ways in which the law is used to control, to guide, and to plan life out of court."100

\footnotetext{
${ }_{97}^{97}$ H L A HART, THE CONCEPT OF LAW (1961) at 43.

${ }^{98} \mathrm{Id}$., at $27 \mathrm{ff}$.

${ }^{99} I d$., at $27-8$.

${ }^{100} I d$., at 40.
} 
How can the idea of legal powers illuminate anything about privacy law? One thing that it helps to highlight is that the idea of liability for an invasion of privacy may in fact be something at the periphery of the legal protection of privacy rather than forming the core legal phenomenon that we must account for. Instead, the core might be bettered captured through ideas associated with the ways in which law facilitates the planning and structuring of our social relations. However, Hart's understanding of private law powers has to do with providing individuals with the ability to create their own rights and duties — to become lawmakers: "[h]e is made competent to determine the course of the law within the sphere of his contracts, trusts, wills, and other structures of rights and duties which he is enabled to build." ${ }^{\prime 101}$ While it is difficult to see how simply from this one could spin out a theory of privacy protection, at least in broad contour the shift from liability to powers is promising. What it provides is a new way of framing the problem: instead of viewing privacy in terms of a sphere to be protected from violation, we should view it as a set of norms that enable individuals to determine some of the basic terms of their social interactions. In other words, we should frame the legal protection of privacy in terms of power rather than in terms of liability.

The second idea that is helpful in breaking away from a rights paradigm is Jeremy Bentham's understanding of expectations. Although well known within the privacy literature for his "Panopticon" — a design for a prison involving such complete surveillance that the prisoner eventually internalizes norms of good behavior - my contention here is that privacy scholars should also pay attention to Bentham's work on expectations. For Bentham, expectation was a kind of future-oriented disposition. Because of this disposition:

${ }^{101} I d$., at 41 . 
Human beings are capable of both planning, structuring, shaping the future and, even more deeply, projecting themselves into that future. Without a secure, reasonably predictable future, such activities would be difficult, perhaps impossible, and surely pointless. But these activities are of enormous value to us, first of all in the sheer delight of exercising these capacities and bringing to completion our own plans and projects. But their value and importance to us runs deeper, for only through such activities can we as individuals shape our identity, and ensure our personal continuity over time. Thus, without security of expectations, we experience both the frustration of curtailment of our liberty to plan for the future and to carry out these plans, and the deeper pain of personal discontinuity, of alienation from our past and future. ${ }^{102}$

Security of expectation becomes foundational for Bentham because it is a necessary precondition for any form of human life, or any conception of well-being. ${ }^{103}$ For Bentham, rational selfdirection requires personal coherence and this is only possibly with personal security and social coherence. Law produces individual liberty indirectly, through creating social coherence. In this way, Bentham's view of law was not primarily regulative - whereby states use law as an instrument to regulate individual behavior — but constitutive. ${ }^{104}$ Its point is "to define, settle, and secure a social reality which makes possible the pursuit of individual aims, purposes, and plans of life." ${ }^{105}$ Indeed, for Bentham this was the point of property law and private law more generally. ${ }^{106}$

Ignoring debates regarding the differences between Hart and Bentham, I want to focus here on a general similarity. The similarity is the emphasis on law's role in enabling individual plans. Again, we can understand this in terms of its contrast with a focus on liability. If we frame law's role as imposing liability in order to protect individual agency—such as in many liberal theories of rights, for example - then we must be able to understand this agency independently of

\footnotetext{
102 Gerald J Postema, Bentham AND the Common LAW Tradition (1986) at 161-2.

${ }^{103} \mathrm{Id}$.

${ }^{104} I d$., at $175,183$.

${ }^{105} I d$., at 175 .

${ }^{106} I d$., at 169 . Note that Bentham defined property very broadly, to include "wealth, reputation, personal integrity (of mind and body), power, rank and condition in life." (Id., at 174.)
} 
the legal liability that protects its violation. If instead we frame law's role as also enabling plans, then the focus shifts to the ways in which law itself helps to constitute agency. For example, law can provide individuals with tools (Hart's legal powers) without which many types of plans are impossible. But Bentham's focus on expectations suggests an even more foundational role for law - that it secures the very preconditions of planning by securing social expectations. It is not that without law that plans go poorly (people do not keep their promises without the threat of liability for breach of contract) or that some plans are not possible (people cannot make some types of financial plans without the ability to alienate their property). The idea is that planning itself is not possible without a framework of law because planning requires the ability to make predictions about how others will behave within the social realm. While there may be some forms of social organization where such expectations are secured without the need for law, in contemporary liberal democracies law is central.

Bentham's views regarding the importance of expectations to the very possibility of planning provides a new way to frame the role of expectations in privacy law. The idea of a "reasonable expectation" of privacy regularly appears in what are otherwise disparate legal regimes as an important way to delineate the scope of privacy protection. Within a rightsparadigm the task is to reinterpret these expectations away from a descriptive account of existing social practices and towards a normative account of a right to privacy. But Bentham suggests an alternative route that is broadly consistent with an understanding of privacy that is rooted in the idea of securing the conditions for self-presentation: settled social expectations regarding audience segregation are essential to the possibility of self-presentation. It is not that the substantive content of the expectations themselves must conform to a particular idea of privacy 
but simply that there be settled expectations so that individuals can understand the basic terms of their social interactions, without which an individual's active role in constructing her social identity becomes impossible.

This can also help us to understand why privacy law has generally developed in tandem with technological change. Often what information and communications technology does is disrupt people's settled expectations regarding audience segregation. Because a camera can record your image, for example, your audience can shift in time and place to include people you never anticipated would be present. What this means is that we now act in contexts where there are developing but no settled social practices (for e.g. social media) or in contexts where settled social practices now are threatened with disruption (for e.g. the nature of our exposure in "public"). The call for law in response to the pressures that new technologies place on privacy is in some important sense a call for law as a means of securing the settled expectations that make the conditions of self-presentation possible.

The third helpful idea in moving away from a rights paradigm is the Rule of Law. There are many different accounts of the Rule of Law, but there is widespread agreement that it at least encompasses Lon Fuller's eight principles of legality. ${ }^{107}$ These are: generality, publicity, nonretroactivity, clarity, non-contradiction, ability to comply, stability, and congruence between rule and enforcement. Considerable disagreement remains concerning whether these principles are, as Fuller claimed, part of the "inner morality" of law, ${ }^{108}$ an expression of law's "virtues"109, or the

\footnotetext{
${ }^{107}$ LON FULLER, THE MORALITY OF LAW (1969).

${ }^{108}$ See NigEL SimMONDS, LAW AS A MORAL IDEAL (2007).

${ }^{109}$ See Joseph Raz The Rule of Law and its Virtue, 93 L.Q.R. 195 (1977).
} 
principles of planning inherent in the legal enterprise. ${ }^{110}$ Deep disagreement also surrounds the issue of whether the Rule of Law goes beyond the formal and procedural aspects described by Fuller and encompasses more substantive concerns such as political and civil rights, or human rights more generally. ${ }^{111}$ My focus here is on Fuller's principles of legality and I propose to bracket the other issues as not relevant to my basic point regarding the helpfulness of this conception of legality.

The principles of legality, taken together, are thought to express the idea that laws should be capable of guiding human action as well as acting as a constraint upon the arbitrary exercise of public power (whether by judges or other officials). This latter sense of the Rule of Law is one that is already connected to the idea of privacy in the constitutional realm and, in particular, in the search and seizure context. Although there is much discussion of "privacy" in search and seizure law there is also-in a tradition stretching back to Entick v. Carrington - a deep an abiding concern regarding the scope of discretionary police authority. ${ }^{112}$ But the guidance function of the law is what I want to focus on here as connected to the first two ideas just outlined as potentially helpful to thinking about the legal protection of privacy.

This guidance function of law is consistent with the ideas of individual planning that underpin both Hart's understanding of legal powers and Bentham's understanding of expectations. Those who instead emphasize the regulatory function of law, and the centrality of

\footnotetext{
110 This view has been recently defended in SCOTT SHAPIRO, LEGALITY (2010).

${ }^{111}$ Paul P. Craig, Formal and Substantive Conceptions of the Rule of Law: An Analytic Framework, PUBLIC LAW 467 (1997); BRIAN TAMANAHA, ON THE RUle OF LAW: HistORY, POLITICS, TheORY (2004).

${ }^{112}$ Entick v. Carrington, 95 ER 807 (King's Bench) 1765. Wilkes was the other high profile case concerning the use of general warrants and seditious libel, which is acknowledged to have a great influence on the drafting of the Fourth Amendment in the US constitution. See Wilkes v. Wood, (1763) 98 Eng. Rep. 489 (K.B.). For an overview of the history of the Fourth Amendment, including different interpretations of this history, see Thomas Y. Davies, Recovering the Original Fourth Amendment, 98 Mich. L. REV. 547 (1999). The Honorable M. Blane Michael, Reading the Fourth Amendment: Guidance From the Mischief that Gave it Birth, 85 N.Y.U.L.REV. 905 (2010).
} 
ideas of liability, understand the guidance function of law in terms of permitting individuals to plan their actions in light of potential legal liability. This connects with the Rule of Law concern for the arbitrary exercise of state power, for if such power is exercised in an arbitrary manner then individuals will never know when they will be subject to it and will not be able to plan their lives in such a way as to avoid its consequences. Such a view often emphasizes a kind of negative freedom, where individuals are permitted to do what the law does not forbid and so clear laws announced in advance are integral to protecting this sphere of freedom. ${ }^{113}$ However, if we shift to thinking that another function of the law is to enable planning in the more constitutive sense already discussed, then we can also see that, as Hart claimed, "c]ertainty and knowledge in advance of the requirements of the law ... is ... crucial for the intelligent exercise of legal powers (e.g. to make wills or contracts) and generally for the intelligent planning of private and public life." 114 In other words, if our concern is not to avoid liability but to rely upon the law in order to secure our future plans (e.g. make a will or create enforceable contractual obligations) then law becomes a tool to reduce the way in which our future plans are subject to the arbitrary whims of others. The guidance function announced by the Rule of Law is not simply about permitting individuals to avoid liability but also points to the role of law in enabling, and even producing, a kind of agency that is otherwise not possible.

How can this picture of law provide a model for the legal protection of privacy? My claim is that this set of ideas, operating outside of the familiar framework of liability, actually provides a strong basis upon which to understand Fair Information Practice-which, I have already indicated, is becoming the dominant model of privacy protection internationally and the basis for data protection legislation in many jurisdictions.

\footnotetext{
${ }^{113}$ See Tamanaha.

${ }^{114}$ Hart, at 250.
} 
While there are variations on the specific components of these practices, the OECD Guidelines remains their most widely-accepted articulation. ${ }^{115}$ They are: Collection Limitation, Data Quality, Purpose Specification, Use Limitation, Security Safeguards, Openness, Individual Participation, and Accountability. Interestingly, the OECD itself had difficulty articulating what these principles are meant to protect:

The remedies under discussion are principally safeguards for the individual which will prevent an invasion of privacy in the classical sense, i.e. abuse or disclosure of intimate personal data; but other, more or less closely related needs for protection have become apparent. Obligations of record-keepers to inform the general public about activities concerned with the processing of data, and rights of data subjects to have data relating to them supplemented or amended, are two random examples. Generally speaking, there has been a tendency to broaden the traditional concept of privacy ("the right to be left alone") and to identify a more complex synthesis of interests which can perhaps more correctly be termed privacy and individual liberties. ${ }^{116}$

The OECD does not articulate which "individual liberties" are at stake in relation to the ideas of openness and individual participation that they mention as examples of the need for a "complex synthesis of interests" that go beyond traditional ideas of privacy violations. Control-based privacy accounts look like an attractive contender for understanding data protection law, as it often has a strong emphasis on individual control and consent. I have argued elsewhere that control-based accounts of privacy cannot account for all of their chief features and a full discussion of this is beyond the scope of the present essay. ${ }^{117}$ What is important here is to show how illuminating it is to look at these principles through the lens of ideas of legality.

One idea that underpins these principles is the need for placing limits on the arbitrary collection and use of personal information. The idea is that collection of information should be

\footnotetext{
115 OECD Guidelines.

${ }^{116} I d$, at para. 2 "General Background" (emphasis added).

${ }^{117}$ See L M Austin, Is Consent the Foundation of Fair Information Practices? Canada's Experience Under PIPEDA, 56 U. T. L. J. 181 (2006) and Reviewing PIPEDA: Control, Privacy and the Limits of Fair Information Practices, 44 CAN. BuS. L. J. 21 (2006).
} 
authorized in some manner-either through lawful authority or through individual consent, that this authorization be specific in relation to a stated purpose, that only information relevant to these purposes be collected, and that use of the information be kept within the scope of this purpose. ${ }^{118}$ The practices and policies of a data controller must be kept "open," which is very much a kind of publicity requirement that works along with the basic principle of accountability to then ensure that personal information collection and use is kept within the boundaries of its lawful authorization. Individuals are entitled to know what information data controllers have collected about them and contest the terms of this collection and use. ${ }^{119}$ Far from a specific idea of privacy, or even rights, the Fair Information Principles look like an articulation of what it means to bring the collection, use, and disclosure of personal information within a regime of law.

Audience segregation lies at the heart of privacy norms, and Fair Information Practices secure this in a manner that is consistent with legal values of publicity. Some of the principles already mentioned, including the Purpose Specification and Openness Principle ensure that information norms are clear to individuals so that they can anticipate the consequences of information collection. Another important norm is the Security Principle. In addition to requiring lawful authority for the collection of personal information, the Collection Limitation Principles calls for information to be collected with the "knowledge or consent of the data subject" where possible. ${ }^{120}$ This provides individual with the ability, at least in some circumstances, of knowing in advance and even accepting the audience of the information in question. Instead of focusing on whether the data controller itself operates within the scope of its authority in relation to the information in question, the Security Principle requires that data be secured against risks such as

\footnotetext{
${ }^{118}$ OECD Guidelines.

${ }^{119} \mathrm{Id}$.

${ }^{120} I d$.
} 
"loss or unauthorised access, destruction, use, modification or disclosure of data" ${ }^{121}$ Security norms here function to preserve audience segregation by imposing obligations to prevent the unintended audience from gaining access to the information.

This analysis suggests that data protection law should be the central paradigm for privacy law. There are numerous practical reasons for thinking that this is the case-including the inaccessibility of the courts to most people and the ironic further publicity required to bring a public claim for invasion of privacy to name just two-but what I am presenting here is a conceptual reason. Data protection law, more than tort law, captures the basic contours of what it means for law to secure the conditions for self-presentation.

\section{Conclusions}

The characteristic gesture of shame is to hide one's face from view. The persistent intuition of a constitutive connection between shame and privacy has contributed to an understanding of privacy that is associated with concealment and hiding. This has been further reinforced by understanding of identity that celebrate the ideal of self-determination free of the influence of others, such that social withdrawal becomes associated with the formation of an authentic self. This self is then understood to be protected through a set of rights that protect its "inviolability." In this essay I have defended the relation between privacy and shame but recast it in order to disengage it from the twin ideals of authenticity and legal rights. The importance of shame does not lie in what society deems "shameful" through its social norms but rather lies in the form of self-consciousness that generates the feeling of shame: my consciousness of the disjunct between

${ }^{121} I d$. 
how I would like others to see me and how they do in fact see me. This self-reflexive view of one's social identity points towards a very different understanding of identity that is protected by privacy norms: not self-determination or self-revelation, with their focus on an authentic self formed through limiting the influence of others, but self-presentation with its focus on the self we seek to create in and through social relations. Privacy is not best understood as a state of social withdrawal but as a set of norms that enable social interaction. Privacy norms ensure some measure of individual control over one's social identity through securing settled expectations in relation to audience segregation that can then be negotiated by an individual— but can also protect the social and interactional aspects of self-presentation and so should not be conflated with simply enabling individual control. The legal model for this understanding of privacy is not legal rights like we find in tort law, for example, but the Fair Information Practices that have come to underpin data protection law internationally.

This analysis brings into view a very different role for law in relation to privacy than is often claimed. Instead of privacy law protecting an already-developed identity from outside pressure, privacy law can help produce identity as it is created through social interaction. Increasingly, our social interactions are mediated through technologies that disrupt the settled social expectations of audience segregation that have developed in the past. In response to this, what we need are information practices governed by law — not just positive laws but the basic legal values that animate ideas like the rule of law that create an environment of stable, predictable norms of audience segregation within which individuals can negotiate their social identities.

This analysis also points us in the direction of other related identity concerns that require more attention from legal scholars. Self-presentation functions well in an environment where the 
reactions of others can be reasonably anticipated based upon shared social understandings.

However, in many contemporary contexts involving information collection and use the reactions of others cannot be reasonably anticipated —instead of shared social understandings, we sometimes interact within contexts of severe information asymmetries. This is especially true in institutional settings. As others have maintained, increasingly individuals are "sorted" into different categories based upon their personal data, without access to why they have been sorted in this way, and sometimes with serious personal consequences. ${ }^{122}$ What this points to is the need to expand our analysis to critically examine these other aspects of identity. But this is an expansion that remains tethered to identity concerns and the manner in which these are undergoing a serious of profound changes and disruptions in the face of contemporary information and communications technology.

If liberal rights were the response to a different era, a challenge to social hierarchies that depended on strategies of abstraction from the particular identities and social contexts of individuals for its emancipatory effect, today we face different challenges. What we need to recover and reimagine is a vocabulary of identity, and a legal framework that supports and enables the conditions of identity, in order to respond to the new challenges of the information society.

\footnotetext{
${ }^{122}$ See Andrew Clement, Toward Identity Rights Beyong Privacy, PRIVACY IN AMERICA: INTERDISCIPLINARY PERSPECTIVES 96 (William Aspreay \& Philip Doty, 2011). For a discussion of information asymmetries as it pertains to internet intermediaries, see Frank Pasquale, Beyond Innovation and Competition: The Need for Qualified Transparency in Internet Intermediaries, 104 NW. U. L. REV. 105 (2010).
} 